\title{
Cold Renal Ischemia: Comparison of Efficacy Between Two Techniques of Cooling, in a Swine Model
}

\author{
Rodrigo Guerra, M.D., Eduardo Piotto Leonardi, M.D., Rodrigo Arthur Otsuka, M.D., \\ Juliany Quitzan, Ph.D., Paulo Roberto Kawano, M.D., Hamilto Akihissa Yamamoto, M.D., \\ João Luiz Amaro, M.D., and Oscar Eduardo H. Fugita, M.D.
}

\begin{abstract}
Objectives: In a swine model of renal ischemia, we compared the effectiveness of the transureteral retrograde cold saline perfusion technique to the traditional method of renal cooling with ice slush, in achieving adequate parenchymal temperatures for functional preservation of the organ. Physiological and histological effects were also assessed.

Methods: Twenty-four domestic male pigs were sampled into four groups to be submitted to a 60-minute ischemia of the left kidney without cooling, with either one of the two cooling techniques (cold saline retrograde perfusion or ice slush), or sham surgery. All of them had also a concomitant right nephrectomy. Renal cortical and medullary temperatures were recorded throughout the experiment. Urinary output was measured, and serum renal function tests were carried on, pre- and postoperatively. After 5 days, the animals were euthanized and their kidneys were submitted to histological analysis.

Results: Mean renal temperature fell in both groups submitted to kidney cooling. With ice slush, a faster drop was observed and a lower minimum temperature was achieved $\left(5.0^{\circ} \mathrm{C}\right.$ in the cortex and $6.3^{\circ} \mathrm{C}$ in the medulla, vs. $25.4^{\circ} \mathrm{C}$ and $24.9^{\circ} \mathrm{C}$ with retrograde cooling). In the other groups, temperature was unchanged. Urinary output and serum creatinine worsened after the experiment, but without significant differences among groups. The histological analysis showed no differences among the four groups, for the studied ischemia time.

Conclusions: Ice slush and retrograde perfusion of cold saline are both effective for cooling the kidney during ischemia. Ice slush is faster in doing so, and it allows much lower temperatures to be achieved in the renal parenchyma. With ischemia time of 60 minutes, no significant differences on the occurrence of functional and histological alterations were detected, even for the group without a cooling procedure.
\end{abstract}

\section{Introduction}

$\mathbf{R}$ ENAL PROCEDURES SUCH AS partial nephrectomy, renal transplantation, and renovascular surgery are clinical situations that may require transitory interruption of renal blood flow. To preserve renal function from injury caused by renal ischemia and reperfusion, different methods to decrease renal metabolism have been described. However, cooling the kidney proved to be one of the most efficient alternatives. Although there are several methods to achieve renal hypothermia, it is usually obtained by involving the kidney with ice slush after clamping the renal artery. ${ }^{1-3}$

Laparoscopic urological surgery greatly evolved in the last decade, and it can be considered as a surgical option to open surgery in most renal procedures, including partial nephrectomy. ${ }^{4}$ However, the ice slush technique becomes very cumbersome and technically challenging, if performed through this approach. ${ }^{5}$ An option could be the perfusion of cold solution in the renal artery, but it is not widely accepted, because of the risks of major damage to the renal vessels. $^{6}$

Landman et $\mathrm{al}^{7}$ and Crain et $\mathrm{al}^{8}$ reported models of endoscopic retrograde renal perfusion with cold saline. They have the potential advantage of easiness to perform, while allowing an operative field without ice and avoiding the cooling of adjacent organs. However, this technique may not be able to provide temperatures low enough to decrease renal metabolism and hence ischemic injury, especially in the proximal convoluted tubule, as it tends to cool the renal medulla better than the renal cortex. ${ }^{9}$

This experimental study intends to compare the effectiveness of the transureteral retrograde cold saline perfusion technique to the traditional method of renal cooling with ice slush, in achieving adequate parenchymal temperatures for

Department of Urology, School of Medicine, São Paulo State University (UNESP), Botucatu, Brazil. 
functional preservation of the organ, as well as to evaluate some of their physiological and histological effects.

\section{Materials and Methods}

The experimental protocol was approved by the Ethics Committee for Animal Experimentation of our institution. Twenty-four domestic male pigs, weighing 15 to $20 \mathrm{~kg}$, were sampled into four groups. After preoperative fasting of 12 hours, they were submitted to sedation with ketamine $(12 \mathrm{mg} / \mathrm{kg})$ and xylazine $(2 \mathrm{mg} / \mathrm{kg})$, inhalatory anesthesia with isoflurane, and were intubated for mechanical ventilation. Vital signs and pulse oximetry were monitored every 15 minutes. Prophylactic enrofloxacin $(30 \mathrm{mg} / \mathrm{kg})$ was administered, and venous hydration with saline $(2 \mathrm{~mL} / \mathrm{kg} / \mathrm{h})$ was ensured throughout the procedure. In all animals, a Gibson incision was performed, and the left kidney was submitted to the experimental conditions described below, followed by nephrectomy of the right kidney:

- Group A: Retrograde ureteral infusion of saline at $4^{\circ} \mathrm{C}$ (eight animals). After cystotomy and identification of the left ureteral meatus, a $6 \mathrm{~F}$ double-lumen ureteral catheter was placed. After occluding the renal pedicle with vascular clamps, retrograde perfusion of saline at $4{ }^{\circ} \mathrm{C}$ was initiated through the catheter, with an infusion pump, at a rate of $30 \mathrm{~mL} /$ minutes. Pelvic drainage occurred through the second lumen of the catheter.

- Group B: External renal cooling with ice slush (eight animals). A sterile surgical glove was adapted as a reservoir for the ice slush, involving the kidney. Right after occlusion of the renal pedicle, the kidney was covered with ice slush (inside the reservoir only, to protect the surrounding structures), which was refilled as needed.

- Group C: Occlusion of the renal pedicle without renal cooling (four animals). Occlusion of the renal pedicle was performed without kidney cooling.

- Group D: Surgical control (four animals). The animals were submitted to the same renal dissection of the previous groups, but without inflicting ischemia or hypothermia on the kidney.

An electronic thermometer (700/4S Gulton) was used to monitor the temperature of the left kidney throughout the procedure. Its steel probes were inserted in the superior and inferior poles of the left kidney, both into the cortex and the medulla (total of four probes), guided by ultrasonography with a 3-MHz linear probe. Temperature was serially measured every 5 minutes, in groups $\mathrm{A}, \mathrm{B}$, and $\mathrm{C}$, during the 60 minutes of ischemia. After clamp releasing and, in groups $A$ and $B$, stopping the cooling method, the temperatures were still measured for 10 more minutes. For group D, temperature was also measured every 5 minutes, for a total time of 70 minutes.

After surgery, opioids were used for postoperative analgesia, and the animals were left in cages that allowed strict measurement of the daily urinary output. Samples of blood and urine were obtained preoperatively and in postoperative days (PODs) 1 and 5, for measurement of serum creatinine and to obtain urine culture.

In POD 5, the animals were sedated (ketamine $12 \mathrm{mg} / \mathrm{kg}$ and xylazine $2 \mathrm{mg} / \mathrm{kg}$ ) and euthanized with potassium chloride, followed by the removal of their kidneys and ureters en bloc. Cortical and medullary tissue specimens were taken from the upper pole, middle section, and lower pole of each kidney for histopathological study. All specimens were stained with hematoxylin and eosin. Two pathologists performed a blinded semiquantitative analysis, and the following alterations were analyzed: tubular hyperplasia, tubular epithelium degeneration, tubular necrosis and dilation, intraluminal protein, mononuclear infiltrate, and congestion. These alterations were graded according to the following criteria: 0 -no alterations, 1 -mild alterations, 2-moderate alterations, 3-severe alterations. The average of points for each variable was obtained in the different groups and used for analysis.

Statistical analysis of the results for each group was performed using variance analysis, for the continuous variables, and Fisher's exact test, for the histological parameters. Differences were considered significant when the $p$-value was $<0.05$.

\section{Results}

The mean renal temperature (MRT) was considered as the average of upper and lower pole temperatures, either cortical or medullary, at each 5-minute interval. During the experiment, the MRT showed a significant drop, in groups A and B (retrograde perfusion and ice slush), both in the cortex and medulla (Fig. 1). This drop was faster and more intense for group B. Nevertheless, the achieved MRTs in group A were significantly below those of groups C (ischemia without cooling) and D (sham).

In group $\mathrm{A}$, the MRT fell at an average rate of $0.37^{\circ} \mathrm{C} /$ minutes, in the medulla, and of $0.28^{\circ} \mathrm{C} /$ minutes, in the cortex, for the first 20 minutes. Thereafter, the medullary temperature stabilized between $26.2^{\circ} \mathrm{C}$ and $24.9^{\circ} \mathrm{C}$, and in the cortex between $27.6^{\circ} \mathrm{C}$ and $25.4^{\circ} \mathrm{C}$. After renal reperfusion and stopping the saline perfusion, return to initial temperatures occurred at $0.58^{\circ} \mathrm{C} /$ minutes at the medulla, and $0.53^{\circ} \mathrm{C} /$ minutes at the cortex. On the other hand, in group $\mathrm{B}$, the MRT fell at an average rate of $1.37^{\circ} \mathrm{C} /$ minutes in the medulla, and $1.44^{\circ} \mathrm{C} /$ minutes in the cortex, for the first 20 minutes. Then the medullary temperature stabilized between $6.5^{\circ} \mathrm{C}$ and $7.8^{\circ} \mathrm{C}$, and in the cortex between $5.0^{\circ} \mathrm{C}$ and $6.8^{\circ} \mathrm{C}$. After renal reperfusion and withdrawal of the ice slush, return to initial temperatures occurred at $2.3^{\circ} \mathrm{C} /$ minutes at the medulla, and $2.4^{\circ} \mathrm{C} /$ minutes at the cortex. In the warm ischemia (WI) and sham surgery groups, there was no decline in MRT whatsoever, remaining close to $35^{\circ} \mathrm{C}$ throughout. The lowest MRTs achieved in the cortex and medulla are presented in Table 1, for each group. Among them, the lowest ones were observed in the animals of group B (ice slush), as previously stated.

A fall in the mean volume of diuresis occurred, in POD 1, followed by progressive normalization, without significant differences among the groups. The mean values of serum creatinine (in $\mathrm{mg} / \mathrm{dL}$ ) ranged from 0.81 to 1.34 , before surgery; from 1.55 to 2.68 , at POD 1 ; and from 1.07 to 2.43 , at POD 5 . These values were not statistically different among the four groups, at each moment $(p>0.05)$. Urine cultures were all negative.

In the histological analysis, no animal presented severe alterations, for each of the studied histological variables. The mean scores for these variables were mostly equal or less than 0.75 and did not go beyond 1.25 , indicating that the histological alterations, in this experimental setting, were mild. There was no statistically significant difference among the four groups, for any histological variable. 
A

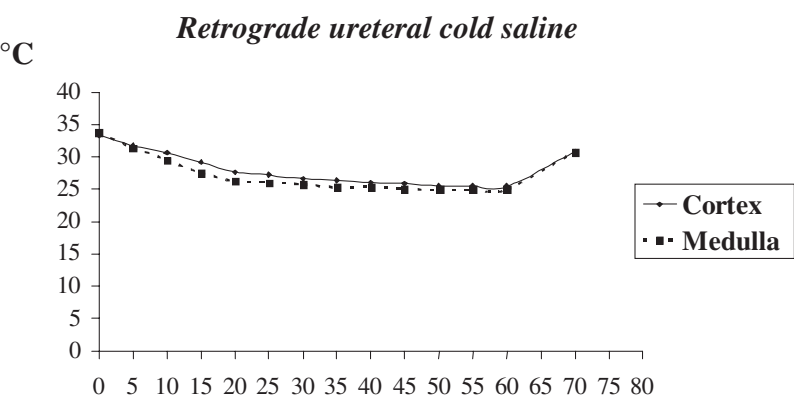

Time (minutes)

C

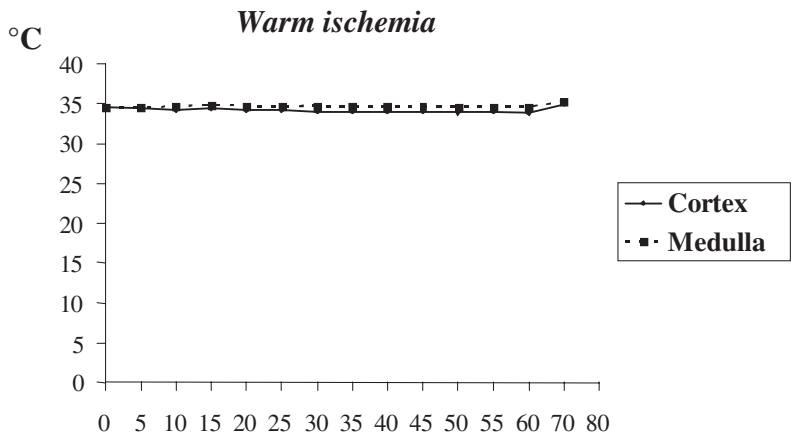

Time (minutes)
B

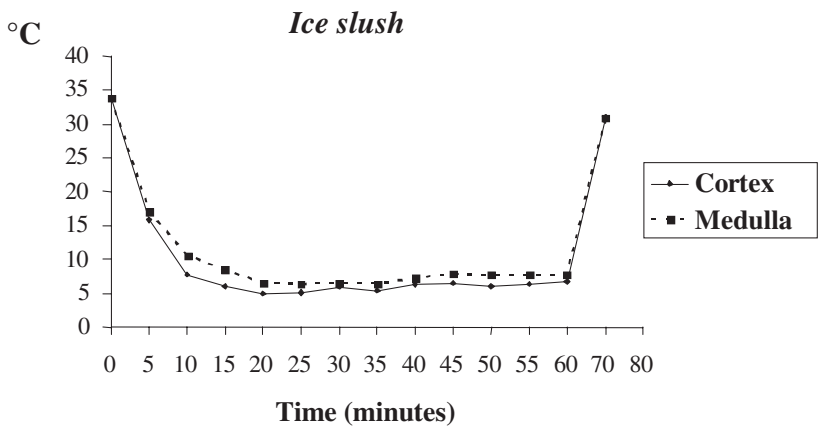

D

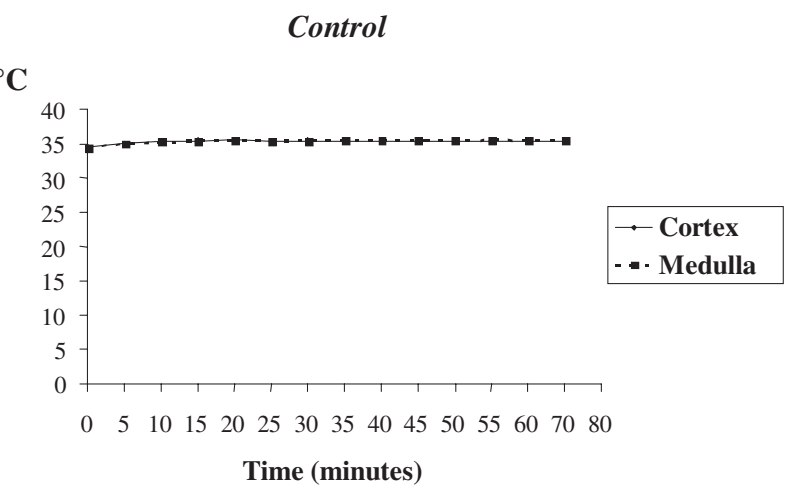

FIG. 1. Mean temperature at the renal cortex and medulla, during the experiment, in groups (A-D).

\section{Discussion}

In 1975 , in a study with dogs, Ward $^{10}$ defined $15^{\circ} \mathrm{C}$ as the ideal cooling temperature to protect the kidneys against ischemia and reperfusion injuries. Wickham et $\mathrm{al}^{11}$ showed that, from $15^{\circ} \mathrm{C}$ to $20^{\circ} \mathrm{C}$, the kidneys of rabbits did not present functional alterations, even for periods up to 3 hours of cold ischemia. In none of our groups in which renal hypothermia was performed it was possible to keep the temperatures close to $15^{\circ} \mathrm{C}$, as temperatures stabilized between $5.0^{\circ} \mathrm{C}$ and $7.8^{\circ} \mathrm{C}$ in the ice slush group, and between $24.9^{\circ} \mathrm{C}$ and $27.6^{\circ} \mathrm{C}$ in the retrograde perfusion group. Nonetheless, no significant histological or functional changes occurred in either group.

In group $\mathrm{A}$, the retrograde perfusion method was more effective in cooling the renal medulla than the cortex, and the renal temperature declined slower than in the ice slush group. After 20 minutes of ischemia, the temperature in the cortex

Table 1. Lowest Mean Temperatures (Average of THe UpPer ANd Lower Pole Temperatures) in Renal Cortex and Medulla of Animals in Groups A-D

\begin{tabular}{lcc}
\hline & \multicolumn{2}{c}{ Lowest mean temperature $\left({ }^{\circ} \mathrm{C}\right)$} \\
\cline { 2 - 3 } Groups & Medulla & Cortex \\
\hline A & 24.9 & 25.4 \\
B & 6.3 & 5.0 \\
C & 35.1 & 35.1 \\
D & 35.3 & 35.3 \\
\hline
\end{tabular}

remained between $25.4^{\circ} \mathrm{C}$ and $27.6^{\circ} \mathrm{C}$. Landman et al ${ }^{7}$ reported $27.3^{\circ} \mathrm{C}$ as the lowest temperatures achieved in the cortex with this method. They chose to control the inflow by gravity, keeping the bag of cool saline $60 \mathrm{~cm}$ above the animal, which provided an infusion rate of $85 \mathrm{~mL} /$ minutes. Crain et $\mathrm{al}^{8}$ obtained $26.1^{\circ} \mathrm{C}$ as the lowest cortical temperature. In our experiment, the infusion rate was $30 \mathrm{~mL} / \mathrm{minutes}$, and in the article by Crain et $\mathrm{al}^{8}$ it was $16.7 \mathrm{~mL} /$ minutes. Therefore, it seems that cold irrigant flow beyond $16.7 \mathrm{~mL} /$ minutes does not provide significant additional cooling effect. In the three studies, the mean temperature in the cortex was at least $10^{\circ} \mathrm{C}$ over ideal, with the method of cold saline retrograde perfusion.

In group B of our study, the ice slush technique cooled the renal cortex better and faster than the renal medulla, reaching a minimum temperature of $5^{\circ} \mathrm{C}$ at the cortex, similar to the results of $\mathrm{Crain}$ et $\mathrm{al}^{8}$ but very distinct from the ones achieved by Landman et $\mathrm{al}^{7}$ who obtained $23.7^{\circ} \mathrm{C}$ as the minimum temperature achieved in the cortex with the ice slush method, as well as a slower decline in renal temperature, when comparing this method to the retrograde saline perfusion. Differences in the weight of the animals may account for these striking differences, as we used smaller pigs, whose smaller kidneys could be possibly more easily cooled, although this was not verified with the retrograde cooling. Anyway, Wickham et $\mathrm{al}^{11}$ showed that temperatures between $5^{\circ} \mathrm{C}$ and $30^{\circ} \mathrm{C}$, during 45 minutes of ischemia, induced little harm to renal function in rabbits. Moreover, in a retrospective study in humans submitted to hypothermia with ice slush, Metzner and Boyce ${ }^{3}$ observed that temperatures around $5^{\circ} \mathrm{C}$ in the renal cortex did not have an impact on renal function. 
The comparison of data from group A (retrograde perfusion) and group B (ice slush) did not show statistically significant functional or histological differences between them, similar to the previous studies. ${ }^{7,8}$ Additionally, when compared with the WI and sham groups, no statistically relevant differences arose among the four groups. It is noteworthy that the animals in group 3 (WI without cooling), submitted to 60 minutes of WI, presented functional and histological results statistically similar to those found in the other groups, including the sham group. However, Landman et $\mathrm{al}^{7}$ have obtained different results concerning this issue, as their study group submitted to WI without cooling presented evident histological findings, such as venous congestion, chronic inflammation, and periarteriolar hemorrhage, which we have not observed even with a longer WI time (WIT) $(30 \times 60$ minutes). Unfortunately, they did not perform any concomitant functional evaluation, which could provide further information on this process. Others have also demonstrated that porcine kidneys can stand WIT of 60 minutes or more. ${ }^{12,13} \mathrm{We}$ attribute the initially diminished urinary output, which was similar in all groups, to surgical stress and to the concomitant performance of right nephrectomy.

Rama Raju et $\mathrm{al}^{9}$ have suggested that WIT above $30 \mathrm{~min}-$ utes may induce irreversible renal damage, but recent studies in the porcine model suggest that the kidneys of these animals tolerate WIT up to 90 minutes. ${ }^{12,13}$ The WIT that a mammal kidney tolerates may vary according to species. Rats tolerate up to 2 hours of renal $\mathrm{WI}^{14}$ and lambs up to 90 minutes. ${ }^{15}$ In rabbits, the renal WIT above 2 hours is fatal. ${ }^{16}$ In humans, 30 minutes is still currently acknowledged as the upper WIT limit, beyond which renal function compromise starts to occur. ${ }^{17}$ The possibility that the human renal cells could tolerate a WIT higher than 30 minutes, like the pig renal cells, would provide enough time to perform laparoscopic nephron-sparing surgery in more complex renal tumors without submitting the kidney to any cooling technique. The WIT affordable by the human kidney without presenting irreversible lesions from ischemia and reperfusion is still controversial. In a recent retrospective study in humans, Thompson et $\mathrm{l}^{18}$ evaluated the impact of WIT in 537 patients with solitary kidneys that underwent open nephron-sparing surgery. They concluded that 20 and 35 minutes are the maximum time that solitary kidneys tolerate WI and cold ischemia, respectively.

Although the porcine kidney is anatomically similar to the human kidney, it is very unlikely that this is the same in regards to renal function. ${ }^{19}$ We believe that establishing the occurrence of ultrastructural cellular alterations because of different renal WIT may help to achieve a better understanding of this process and, possibly, more accurately compare the animal models to human beings. Additionally, long-term studies of renal function after temporary WI are lacking.

\section{Conclusions}

Both ice slush and retrograde infusion of cold saline are effective for cooling the kidney. However, ice slush is faster in doing so and provides much lower renal parenchymal temperatures. Neither technique is able to keep the renal temperature close to $15^{\circ} \mathrm{C}$. In spite of this, functional or histological alterations have not been detected. In the absence of a cooling procedure, such alterations were not observed as well, suggesting that the porcine kidney can stand a 60-minute WI without significant damage. So, additional research should be directed to further clarify this issue.

\section{Acknowledgments}

We acknowledge Dr. Reneé Laufer Amorim and Dr. Marcela Marcondes Pinto Rodrigues (Department of Veterinarian Pathology, UNESP) for histological examination of the specimens. Fundação de Amparo à Pesquisa do Estado de SãoPaulo (FAPESP) provided grants to this research. There was no other financial support as well as no conflict of interests.

\section{Disclosure Statement}

No competing financial interests exist.

\section{References}

1. Wagenknecht LV, Hupe W, Bucheler E, Klosterhalfen H. Selective hypothermic perfusion of the kidney for intrarenal surgery. Eur Urol 1977;3:62-68.

2. Cockett AT. The kidney and regional hypothermia. Surgery 1961;50:905-910.

3. Metzner PJ, Boyce WH. Simplified renal hypothermia: An adjunct to conservative renal surgery. Br J Urol 1972;44: 76-85.

4. Gill IS, Matin SF, Desai MM, et al. Comparative analysis of laparoscopic versus open partial nephrectomy for renal tumors in 200 patients. J Urol 2003;170:64-68.

5. Gill IS, Abreu SC, Desai MM, et al. Laparoscopic ice slush renal hypothermia for partial nephrectomy: The initial experience. J Urol 2003;170:52-56.

6. Janetschek G, Abdelmaksoud A, Bagheri F, et al. Laparoscopic partial nephrectomy in cold ischemia: Renal artery perfusion. J Urol 2004;171:68-71.

7. Landman J, Rehman J, Sundaram CP, et al. Renal hypothermia achieved by retrograde intracavitary saline perfusion. J Endourol 2002;16:445-449.

8. Crain DS, Spencer CR, Favata MA, et al. Transureteral saline perfusion to obtain renal hypothermia: Potential application in laparoscopic partial nephrectomy. ISLS 2004; 8:217-222.

9. Rama Raju BV, Atm Prakash, Kapur M, et al. Acute renal ischemia and the effect of local hypothermia on the histological changes: An experimental study. Indian J Med Res 1969;57:925-931.

10. Ward JP. Determination of the optimum temperature for regional renal hypothermia during temporary renal ischaemia. Br J Urol 1975;47:17-24.

11. Wickham JEA, Hanley HG, Joekes AM. Regional renal hypothermia. Br J Urol 1967;39:727-743.

12. Laven BA, Orvieto MA, Chuang MS, et al. Renal tolerance to prolonged warm ischemia time in a laparoscopic versus open surgery porcine model. J Urol 2004;172(6 Pt 1): 2471-2474.

13. Baldwin DD, Maynes LJ, Berger KA, et al. Laparoscopic warm renal ischemia in the solitary porcine kidney model. Urology 2004;64:592-597. 
14. Koletsky S. Effects of temporary interruption of renal circulation in rats. AMA Arch Path 1954;58:592-603.

15. Mitchel RM. Studies on renal transplantation in sheep. Aust NZ J Surg 1959;28:263-273.

16. Badenoch AW, Damady EM. The effect of temporary occlusion of the renal artery in rabbits and relationship to traumatic uremia. J Pathol Bacteriol 1947;59:79-94.

17. Novick AC. Renal hypothermia: In vivo and ex vivo. Urol Clin North Am 1983;10:637-644.

18. Thompson RH, Frank I, Lohse CM, et al. The impact of ischemia time during open nephron sparing surgery on solitary kidneys: A multi-institutional study. I Urol 2007;177: 471-476.

19. Thomsen HS, Larsen S, Talner LB. Papillary morphology in adult human kidneys and in baby and adult pig kidneys. Eur Urol 1983;9:170-180.
Address correspondence to: Oscar Eduardo H. Fugita, M.D. Departamento de Urologia Faculdade de Medicina de Botucatu (UNESP) Distrito de Rubião JR., S/N Botucatu-SP, 18618-970 Brazil

E-mail: fugita@fmb.unesp.br
Abbreviations Used
$\mathrm{MRT}=$ mean renal temperature
$\mathrm{POD}=$ postoperative day
$\mathrm{WI}=$ warm ischemia
$\mathrm{WIT}=$ warm ischemia time 

This article has been cited by:

1. J. Colli, K. Cotter, P. Dorsey, G. Mitchell, B. R. Lee. 2012. Intrarenal pressures remain low with placement of a dual lumen catheter for retrograde irrigation to induce renal hypothermia. International Urology and Nephrology 44:5, 1425-1429. [CrossRef] 